\title{
Study of Diagnostic Nasal Endoscopy and Sinonasal Grading
}

\author{
Mohana Karthikeyan $\mathbf{S}^{1^{*}}$, Jacith C. Cornellius ${ }^{2}$ \\ ${ }^{1 *}$ Assistant Professor, Department of ENT, \\ Karpaga Vinayaga Institute of Medical Sciences, Maduranthagam, Kancheepuram, India. \\ 2Upgraded Institute of Otorhinolaryngology, \\ Institute of Speech and Hearing, Madras Medical College and Government General Hospital, Chennai, India.
}

\begin{abstract}
Introduction: Endoscopes have markedly improved visualization for sinus surgery, but expanding concepts of FESS have outplaced available operative instrumentation. The surgical techniques are continually improved, but the basic concepts of the newer instruments have changed very little.

Methods: The main objective of this study is to study the diagnostic nasal endoscopy and sinonasal grading. A total of 60 cases who are diagnosed to have sinonasal polyposis were included in this study. By using 30 degree Hopkin's rod endoscope of $1^{\text {st }}, 2^{\text {nd }}$ and $3^{\text {rd }}$ pass were done. Middle meatus was examined in all patients and the polyps were graded according to the standard classification.
\end{abstract}

Results: Thirty five males and 25 females were included and maximum number of cases belongs to the age group of 31 to 40 years. Among the grading of polyps, 13, 33 and 14 are supported 1, 2 and 3 polyps respectively. The blood loss during surgery was found maximum as $160 \mathrm{ml}$ among 1 case and maximum of 13 cases lost $120 \mathrm{ml}$ of blood.

Conclusion: An understanding of technical aspects of powered instrumentation has led to optimize the choice of

\section{INTRODUCTION}

Evaluation of the accuracy of objective diagnostic modalities for chronic rhinosinusitis (CRS) and their comparison to each other to reach the correct diagnosis with minimum cost and highest accuracy are now a interesting area of research and diagnosis. Nasal polyposis with CRS is classified as a subset of chronic rhinosinusitis. The presence of asthma, aspirin intolerance or both adversely affect endoscopic sinus surgery outcome. ${ }^{1}$ Many studies have examined the prognostic factors affecting the success of endoscopic sinus surgery (ESS) and a history of previous ESS is generally regarded as a factor contributing to a poor surgical outcome. ${ }^{2}$

Revision functional endoscopic sinus surgery benefits patients that fail maximum medical therapy and prior sinus surgery for CRS by objective and subjective measures. ${ }^{3}$ Nasal endoscopy involves evaluation of the nasal and sinus passages with direct vision using a magnified high quality view. Nasal endoscopy may be accomplished with either a flexible fiberoptic endoscope or a rigid endoscope. When performed by experienced practitioners, both flexible endoscopy and rigid endoscopy are usually well tolerated. The indications for nasal endoscopy including initial identification of disease in patients experiencing sinonasal practicing surgeon in endoscopic sinus surgery. The preoperative blood loss was found minimal in this study even for grade III polyposis also.

Keywords: Nasal endoscopy, Sinonasal grading, Diagnosis *Correspondence to:

Dr. Mohana Karthikeyan S,

Assistant Professor, Department of ENT, Karpaga Vinayaga Institute of Medical Sciences, Maduranthagam, Kancheepuram, India

Article History:

Received: 23-08-2016, Revised: 28-08-2016, Accepted: 15-09-2016

\begin{tabular}{|l|c|}
\hline \multicolumn{2}{|c|}{ Access this article online } \\
\hline Website: & Quick Response code \\
www.ijmrp.com & \\
\hline DOI: & \\
10.21276/ijmrp.2016.2.5.018 & \\
\hline
\end{tabular}

symptoms; evaluation of patients response to medical treatment including resolution of polyps, unilateral disease, patients with complications or impending complications of sinusitis; recurrence of pathology after FESS; biopsy of nasal masses or lesions; nasopharynx for lymphoid hyperplasia and nasal obstruction; cerebrospinal fluid leak; treatment of epistaxis; hyposmia or anosmia; treatment of nasal foreign bodies; obtaining a culture of purulent secretions and debridement and removal of crusting, mucus and fibrin from obstructed nasal and sinus cavities. ${ }^{4,5}$

With currently available FES instruments, surgeons often find that they do little short of the precise surgery demanded by the functional approach. Consequently, the need of meticulous cutting, a near bloodless filed, unimpaired vision and continuous removal of resected tissue remains elusive are observed. ${ }^{3}$ The instruments used so far tend to strip the mucosa from the underlying bone that predisposes to increased bleeding, which is the archenemy of the surgeon, because it tends to decreased visibility, the cornerstone of complications. The lack of continuous suction at the operative site is a technical limitation that compounds the stress for the surgeon and increases the inherent risk for the patient. 3,6 
Attention was therefore directed towards laser but is has some disadvantages of post-operative scaring and necrosis. The microdebrider facilitates preservation of mucosa and vital structures by resecting diseased, obstructive tissue with very limited blood loss. ${ }^{3}$ Simultaneous continuous suction at the operative site is a marked benefit of this instrument which helps to overcome the well-recognized problem of blood pooling that increases the potential for surgical morbidity. Thus the main objective of this study is to study the diagnostic nasal endoscopy and sinonasal grading among cases diagnosed to have sinonasal polyposis.

\section{MATERIALS AND METHODS}

\section{Study design and population}

Patients diagnosed as sinonasal polyposis in Upgraded Institute of Otorhinolaryngology, Government Rajiv Gandhi General Hospital and Madras Medical College, Chennai. The study was conducted from July to September in which 60 cases were included in this study.

Inclusion criteria of the subjects are age group above 12 years and below 60 years, and patients undergoing endoscopic sinus surgery for sinonasal polyposis.

Exclusion criteria are age below and above 12 and 60 years respectively, subjects who are not willing to enrol and nasal endoscopic surgeries for pathologists like skull base lesions, pituitary surgeries and chronic dacryocystitis and tumors.

\section{Nasal endoscopy}

All the patients underwent diagnostic nasal endoscopy who are willing and gave written consent are included. By using 30 degree Hopkin's Rod endoscopy was used where $1^{\text {st }}, 2^{\text {nd }}$ and $3^{\text {rd }}$ pass were done. Middle meatus was clearly examined in all the patients subjected to this investigation and polyps were graded appropriately.

\section{Grading of sinonasal polyps}

According to the standard classification system, the observed and noted polyps were graded into 4 major types:

1. Grade 0 - No polyps present

2. Grade I - Polyps confined to middle meatus

3. Grade II - Polyps beyond middle meatus (reaching inferior turbinate or medial to middle turbinate)

4. Grade III - Polyps almost or completely obstructing nasal cavity.
Associated septal deviations, turbinate hypertrophy, position of uncinate process, sphenoethmoidal recess and nasopharynx were examined. Further, the accessibility to the middle meatus was also analyzed.

\section{Assessment of blood loss during surgery}

The blood collected in suction apparatus and the amount of saline irrigation was measured. The amount of saline was subtracted from the blood collected in suction. The blood collected from individual subjects was charted out according to their grade of polyposis in millilitres.

\section{RESULTS}

In this study, sixty patients were subjected for surgery, where 35 patients (58\%) were males and 25 patients (42\%) were females. The detailed description of the number of male and female subjects studied was depicted in Fig 1.

\section{Fig 1: Sex wise distribution of subjects}

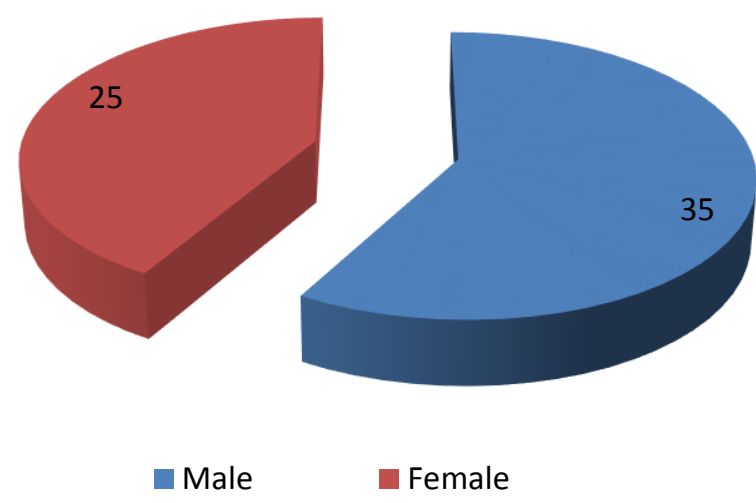

The age distribution of the patients was between 14 and 60 years. The maximum number of cases was identified in the age group of 31 to 40 years followed by 21 to 30 years. Only one case was recorded in the age group of 51 to 60 years. Table 1 denoted the age wise distribution of subjects enrolled for this study.

Out of 60 patients enrolled in this study, $13(21.7 \%)$ showed Grade I polyps, $33(55 \%)$ had Grade II polyps and $14(23.3 \%)$ had Grade III polyps. The grade II polyps were observed in maximum number of patients. Fig 2 impregnated with number of patients supported with grades of polyps. None of cases supported the Grade 0.

Table 1: Age wise distribution of patients

\begin{tabular}{lccc}
\hline Age groups in years & Male $(\mathbf{n}=\mathbf{3 5})$ & Female $(\mathbf{n}=\mathbf{2 5})$ & Total $(\mathbf{n}=\mathbf{6 0})$ \\
\hline $\mathbf{1 4} \mathbf{- 2 0}$ & 5 & 4 & $9(15)$ \\
$\mathbf{2 1}-\mathbf{3 0}$ & 14 & 3 & $17(28.3)$ \\
$\mathbf{3 1}-\mathbf{4 0}$ & 11 & 16 & $27(45)$ \\
$\mathbf{4 1}-\mathbf{5 0}$ & 5 & 1 & $6(10)$ \\
$\mathbf{5 1}-\mathbf{6 0}$ & - & 1 & $1(1.7)$ \\
\hline
\end{tabular}

[Figure in parenthesis denoted percentages expressed for age groups]

Among the patients including in this study maximum of $120 \mathrm{ml}$ blood loss was found among 13 patients followed by $100 \mathrm{ml}$ among 10 cases and $110 \mathrm{ml}$ among 9 cases. The least and maximum among of blood loss including 80 and $200 \mathrm{ml}$ was found among 3 and 2 cases respectively. The average blood loss was found to be $123 \mathrm{ml}$ and the maximum cases with high blood loss was found in the range of 100 to $140 \mathrm{ml}$. Table 2 highlighted the amount of preoperative blood loss among subjects included. 
Fig 2: Grading the polyps among study patients

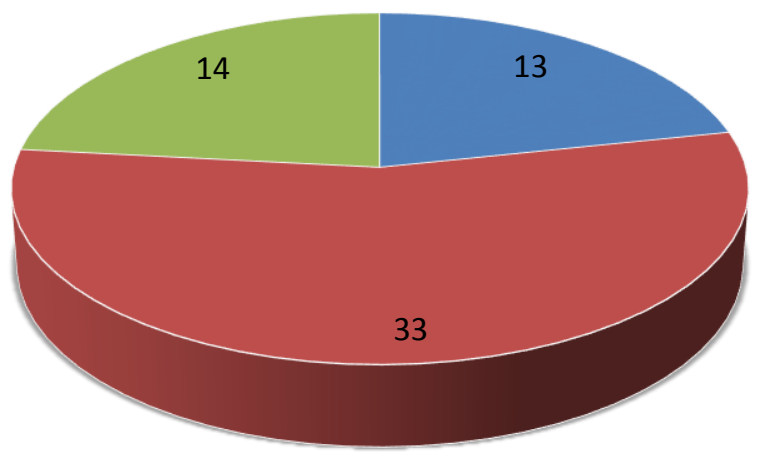

- Grade I - Grade II — Grade III
Table 2: Peroperative blood loss

\begin{tabular}{lc}
\hline Blood loss range & Number of patients \\
\hline $\mathbf{8 0}$ to $100 \mathrm{ml}$ & $15(25)$ \\
101 to $120 \mathrm{ml}$ & $22(36.7)$ \\
121 to $140 \mathrm{ml}$ & $14(23.4)$ \\
141 to $160 \mathrm{ml}$ & $5(8.3)$ \\
161 to $180 \mathrm{ml}$ & $2(3.3)$ \\
181 to $200 \mathrm{ml}$ & $2(3.3)$
\end{tabular}

[Figure in parenthesis denoted percentages expressed for age groups

Out of 13 patients with Grade I polyps, the average blood loss was found to be $100.8 \mathrm{ml}$. In Grade II with 33 patients and Grade III polyps with 14 patients, the average blood loss was found to be 119 and $152 \mathrm{ml}$ respectively. The average blood loss for the 8 patients who had no pre-operative preparations was $126 \mathrm{ml}$. Figure 3 denoted the average amount of blood loss in relation with grades during surgery.

Fig 3: Blood loss verses grades of polyps during surgery

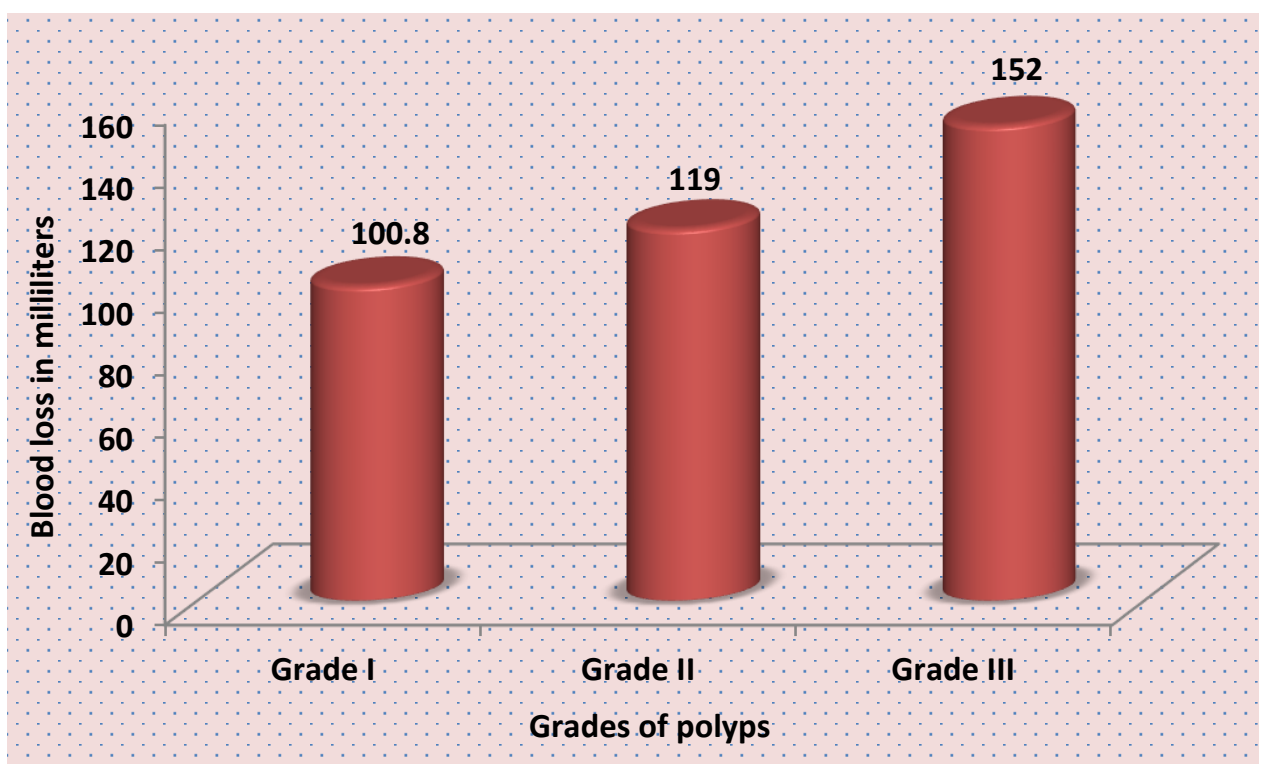

\section{DISCUSSION AND CONCLUSION}

The current definition of CRS was defined in 1996 according to the subjective data. The accuracy and validity of such definition has been questioned in this investigation. ${ }^{5,7}$ The later revision in 2002 emphasized the need of reconfirm CRS by adopting physical evidence of mucosal changes and asserted that such concrete signs and symptoms including purulent drainage, polyps, polypoid changes, localized mucosal edema, erythema and granulations are needed to reach a definitive diagnosis. Thus the inclusion of nasal endoscopy and grading the polyps were impregnated in this study. ${ }^{8}$

From the literature, it appears that nasal endoscopy provides more important objective evidence of CRS and corroborates findings with polyps grades in the majority of patients. $6,9,10$ In some cases, infections also found with harvesting of inflammatory mediators or eosinophils. ${ }^{8}$ The radiographical diagnosis may not ne indicated in this study, thus it could probably be considered when the symptoms persist in spite of medical therapy or when a surgical intervention is needed. The presence of mucosal changes or polyps seen on endoscopy in CRS is a good indicator and highly sensitive in predicting sinus involvement and therefore does not require routine radioimaging.

Some studies highlighted the high incidence of asymptomatic sinus disease in normal population where the role of endoscopy in this subgroup of patients could be addressed4,11 in the current study and it is therefore a limiting factor of the study along with the inclusion of small minority of patients with CRS.

\section{REFERENCES}

1. Guerrero J, Molina B, Echeverria L, Arribas I and Rivera T. "Endoscopic sinonasal surgery: study of 110 patients with nasal polyposis and chronic rhinosinusitis". Acta Otorrhinolaryngology Experiments. 2007;58:252-6.

2. Lee JY, Lee SW and Lee JD. "Comparison of the surgical outcome between primary and revision endoscopic sinus surgery for chronic rhinosinusitis with nasal polyposis". American Journal of Otolaryngology. 2008;29:379-84.

3. McMains KC and Kountakis SE. "Revision functional endoscopic sinus surgery: objective and subjective surgical outcomes". American Journal of Rhinology. 2005;19 344-47. 
4. Havas TE, Motbey JA and Gullane PJ. "Prevalence of incidental abnormalities on computed tomographic scans of the paranasal sinuses". Achieves of Otolaryngology Head Neck Surgery. 1988;114:856-59.

5. Lanza DC and Kennedy DW. "Adult rhinisinusitis defined". Otolaryngology Head Neck Surgery. 1997;117:1-7.

6. Senior BA, Kennedy DW, Tanabodee J, Kroger H, Hassab M and Lanza D. "Long term results of functional endoscopic sinus surgery". Laryngoscope. 1998;108:151-57.

7. Arif AK, Roshna RP, Mary K, Shyam K, Rashid AA and Kurien

T. "Diagnosis of adult chronic rhinosinusitis: can nasal endoscopy predict intrasinus disease". Oman Medical Journal. 2013;28:42731.

8. Benninger MS, Ferguson BJ, Hadley JA, Hamilos DL, Jacobs M and Kennedy DW. "Adult chronic rhinosinusitis: definitions, diagnosis, epidemiology and pathophysiology". Otolaryngology Head Neck Surgery. 2003;129:1-32.

9. Stankiewicz JA and Chow JM. "Nasal endoscopy and the definition and diagnosis of chronic rhinosinusitis". Otolaryngology Head Neck Surgery. 2002;126:623-27.
10. Rosbe KW and Jones KR. "Usefulness of patient symptoms and nasal endoscopy in the diagnosis of chronic sinusitis". American Journal of Rhinology. 1998;12:167-71.

11. Lyoyd GA. "CT of the paranasal sinuses: study of a control series in relation to endoscopic sinus surgery". Journal of Laryngology and Otology. 1990;104:477-81.

Source of Support: Nil. Conflict of Interest: None Declared.

Copyright: (c) the author(s) and publisher. IJMRP is an official publication of Ibn Sina Academy of Medieval Medicine \& Sciences, registered in 2001 under Indian Trusts Act, 1882.

This is an open access article distributed under the terms of the Creative Commons Attribution Non-commercial License, which permits unrestricted non-commercial use, distribution, and reproduction in any medium, provided the original work is properly cited.

Cite this article as: Mohana Karthikeyan S, Jacith C. Cornellius. Study of Diagnostic Nasal Endoscopy and Sinonasal Grading. Int J Med Res Prof. 2016; 2(5):93-96. 